\title{
edmetic
}

Revista de Educación Mediática y TIC

\section{El estado de la cuestión: El valor de las experiencias tecnológicas educativas}

El crecimiento de las experiencias tecnológicas educativas va de la mano de las modificaciones que las ecologías de las aulas de los diferentes niveles educativos van reclamando. Según avanzamos en este siglo XXI, los cambios en las demandas sociales han provocado que los docentes den un giro de tuerca a las metodologías de clase, orientadas, fundamentalmente, hacia la búsqueda de una mejora no solo del propio proceso de enseñanzaaprendizaje, sino también del clima en que este debe implementarse.

Los centros educativos, ya sean de enseñanza infantil ya de estudios superiores, necesitan de la voluntariedad de sus profesores en lo que se refiere a la introducción de las herramientas tecnológicas. Es de agradecer que esta implicación venga muchas veces auspiciada no solo por la curiosidad de los estudiantes por conocer desde otra óptica el contenido o ampliarlo, sino también por los propios educadores, los cuales dedican un inestimable tiempo en pro de estas llamadas innovaciones metodológicas.

La realidad actual es que los recursos llamemos 2.0 están ahí, y somos nosotros los profesores los que en primera instancia debemos incorporar a nuestra acción educativa. Todo ello va a conllevar que el reciclaje sea continuo, sin embargo consideramos que el resultado bien merece la pena el tiempo dedicado.

Continuando con el número anterior, en esta ocasión se presentan acciones educativas que desde diferentes partes del planeta los docentes 
están llevando a cabo en pro de esa mejora a la que antes nos referíamos. El empleo de herramientas tales como los mapas mentales, los cuales permiten al estudiante una concreción mayor en la adquisición del conocimiento o los flash mob, pone de relieve las posibilidades que este tipo de herramientas tienen como es por ejemplo el potenciar el trabajo colaborativo y cooperativo de alumnado y profesorado al imbricar varias áreas curriculares.

Todas estas experiencias nos llaman de nuevo la atención sobre las grandes posibilidades que las herramientas 2.0 tienen para que el aprendizaje sea efectivo y eficaz.

Verónica Marín-Díaz

Editora EDMETIC, Revista de Educación Mediática y TIC vmarin@uco.es 